\title{
Highly Sensitive Detection of Proteins Separated by Capillary Zone Electrophoresis Using On-Line Chemiluminescence Detection
}

\author{
Tadashi Hara, Hisashi Nishida and Riichiro NakajIma \\ Department of Chemical Engineering, Faculty of Engineering, Doshisha University, \\ Karasuma Imadegawa, Kyoto 602, Japan
}

Keywords Chemiluminescence detection, on-line, protein, capillary electrophoresis, stacking

In a previous study ${ }^{1}$, Rhodamine $B$ isothiocyanate (RITC) was used as a dyestuff for labeling proteins so as to improve the sensitivity of on-line chemiluminescence detection (CLD) of proteins separated by capillary zone electrophoresis (CZE) in a phosphate buffer solution (pH 3.5). Using this method bovine serum albumin (BSA) in the concentration range of $7 \times 10^{-8}-7 \times 10^{-6} \mathrm{M}$ ( $1 \mathrm{M}=1 \mathrm{~mol} \mathrm{dm}^{-3}$ ) could be determined with a lower detection limit of $5 \times 10^{-8} \mathrm{M}$ (absolute amounts, $1 \mathrm{fmol}$ ). Since RITC was not examined in an alkaline solution, RITC was used at pH 9.0 in the present study. Tetramethylrhodamine isothiocyanate isomer $R$ (TRITC), which is expected to be similarly sensitive as RITC, has also been examined at pH 9.0. TRITC gave a better result than did RITC. The result obtained was as follows: $c a$. $1 \times 10^{-6} \mathrm{M}$ of BSA could be determined using TRITC in about $20 \mathrm{~min}$ with a detection limit of $1 \times 10^{-8}$ $\mathrm{M}$, corresponding to $200 \mathrm{amol}$ of BSA. Using the method of stacking ${ }^{2,3}$ for the sample components across the concentration boundary between the sample and background electrolyte, $c a$. $1 \times 10^{-7} \mathrm{M}$ of BSA could be further determined using TRITC in about 20 min with a detection limit of $6 \times 10^{-9} \mathrm{M}$.

\section{Experimental}

\section{Reagents}

All of the reagents used were commercially available and of analytical-reagent grade. Deionized water was distilled before use. Each $1 \times 10^{-4} \mathrm{M}$ solution of RITC and TRITC was prepared by dissolving them in a carbonate buffer solution (pH 9.0). BSA, bovine serum $\gamma$ globulin (B $\gamma \mathrm{G}$ ), ovalbumin (Ova), $\alpha$-lactalbumin ( $\alpha$ lacta) (molecular weights of 66296, 150000, 42699 and 14200 , respectively) dissolved in a $25 \mathrm{mM}$ carbonate buffer solution were used, except for the stacking experiments. An acetonitrile solution containing hydrogen peroxide $\left(\begin{array}{lll}30 \% & \left.\mathrm{H}_{2} \mathrm{O}_{2}\right)\end{array}\right.$ and bis(2,4,6-trichlorophenyl) oxalate (TCPO) was used as a chemiluminescence (CL) reagent solution.

\section{Apparatus}

The experiment was carried out using the same apparatus as that reported regarding a previous experiment. 4,5

\section{Procedures}

A freshly available capillary tube was treated with $1 \mathbf{M}$ hydrochloric acid for $10 \mathrm{~min}$, and then washed with distilled water before use. The carrier solution was filtered through a Millipore (Millex-GSSLG0250S) filter and degassed before use. The capillary tube was filled with a carrier solution by means of a $100 \mu l$ microsyringe before use. First of all, a high voltage was applied while feeding an imidazole buffer solution alone at a rate of $5 \mu \mathrm{min}^{-1}$ using a syringe pump. Then, the $\mathrm{CL}$ reagent solution containing $\mathrm{H}_{2} \mathrm{O}_{2}$ and TCPO was fed at a rate of $30 \mu \mathrm{min}^{-1}$ by another pump until a steady electrolytic current was obtained. A sample solution, which was left standing for $4 \mathrm{~h}$ after mixing of a dye-stuff and a protein, was introduced into the capillary tube by siphoning after the high voltage had been switched off. A high voltage ranging from 0 to $20 \mathrm{kV}$ was gradually applied over a period of twenty seconds while operating the pumps. The CL measurement was started as soon as the voltage reached $20 \mathrm{kV}$. In accordance with a method of Burgi ${ }^{2,3}$, stacking a TRITC-BSA complex was also attempted.

\section{Results and Discussion}

Both the spectrophotometric and CZE properties of proteins, dye-stuffs, and complexes were examined, and the following results were obtained. The absorption spectra of TRITC and its BSA complex in the wavelength region between 400 and $800 \mathrm{~nm}$ were almost the same, and showed maximum absorption at $548 \mathrm{~nm}$. A mixed solution (pH 9.0) of TRITC and BSA was subjected to CZE; the two electropherograms shown in Fig. 1 (A) and (B) were at 548 and $210 \mathrm{~nm}$, respectively. The third electropherogram (C) was obtained at $548 \mathrm{~nm}$ for TRITC alone (Fig. 1 (C)). As can be seen from Fig. 1, TRITC 


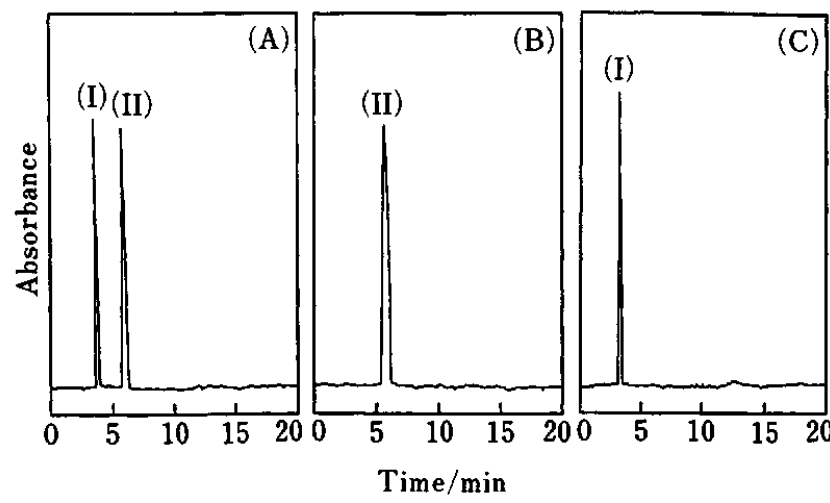

Fig. 1 Electropherograms of TRITC and the TRITC-BSA complex with UV-VIS detection. Capillary, $60 \mathrm{~cm}, 50 \mu \mathrm{m}$ i.d., fused silica; separation distance, $35 \mathrm{~cm}$; applied voltage, $20 \mathrm{kV}$; buffer, $25 \mathrm{mM}$ carbonate (pH 9.0). Sample solutions were prepared by dissolving TRITC (and BSA) in an electrophoretic buffer. (A) BSA and TRITC, detected at $548 \mathrm{~nm}$. (B) BSA and TRITC, detected at $210 \mathrm{~nm}$. (C) TRITC, detected at $548 \mathrm{~nm}$. The BSA and TRITC concentrations were $1 \times 10^{-5} \mathrm{M}$ and $2 \times 10^{-4} \mathrm{M}$, respectively. Peaks: $(\mathrm{I})=$ TRITC,$(\mathrm{II})=$ TRITC-BSA complex.

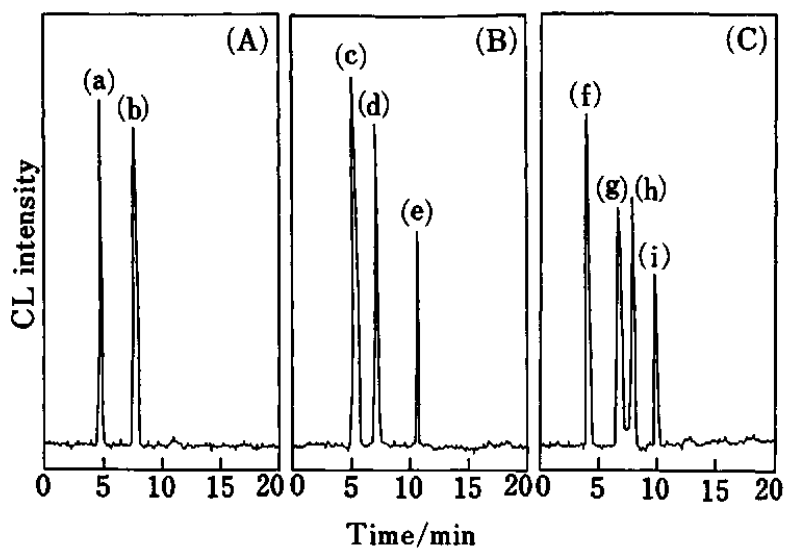

Fig. 2 Electropherograms of TRITC-protein complexes detected by CL. Capillary, $80 \mathrm{~cm}, 50 \mu \mathrm{m}$ i.d., fused silica; applied voltage, $20 \mathrm{kV}$; buffer, $25 \mathrm{mM}$ carbonate ( $\mathrm{pH} \mathrm{9.0).}$ TCPO-CL reaction conditions: (1) $1 \mathrm{mM} \mathrm{TCPO}$ and $100 \mathrm{mM}$ hydrogen peroxide in acetonitrile and (2) $200 \mathrm{mM}$ imidazole buffer (pH 6.15). All sample solutions were prepared by dissolving protein(s) and RITC or TRITC in the electrophoretic buffer. (A) BSA $\left(8 \times 10^{-7} \mathrm{M}\right)$ and TRITC (4× $\left.10^{-5} \mathrm{M}\right),(\mathrm{B})$ Ova $\left(1 \times 10^{-6} \mathrm{M}\right), \alpha$-lacta $\left(1 \times 10^{-6} \mathrm{M}\right)$ and RITC $\left(5 \times 10^{-5} \mathrm{M}\right)$, (C) B $\gamma \mathrm{G}\left(8 \times 10^{-7} \mathrm{M}\right)$ BSA $\left(8 \times 10^{-7} \mathrm{M}\right)$, $\alpha$-lacta $\left(8 \times 10^{-7} \mathrm{M}\right)$ and TRITC $\left(4 \times 10^{-5} \mathrm{M}\right)$. Peaks: (a) and $(\mathrm{f})=$ TRITC, (b)=TRITC, (c)=TRITC-BSA, (d)=RITC-Ova, (e) $=$ RITC- $\alpha$-lacta, $\quad(\mathrm{g})=$ TRITC-B $\gamma \mathrm{G}, \quad(\mathrm{h})=$ TRITC-BSA, (i) $=$ TRITC- $\alpha$-lacta.

was found to co-migrate with BSA in CZE, since peaks (I) and (II) in (A) corresponded to peak (I) in (C) and peak (II) in (B), respectively. A similar result to this was also obtained for a RITC-BSA complex. Figure 2 shows electropherograms of RITC-protein complexes and TRITC-protein complexes detected by CL. On the

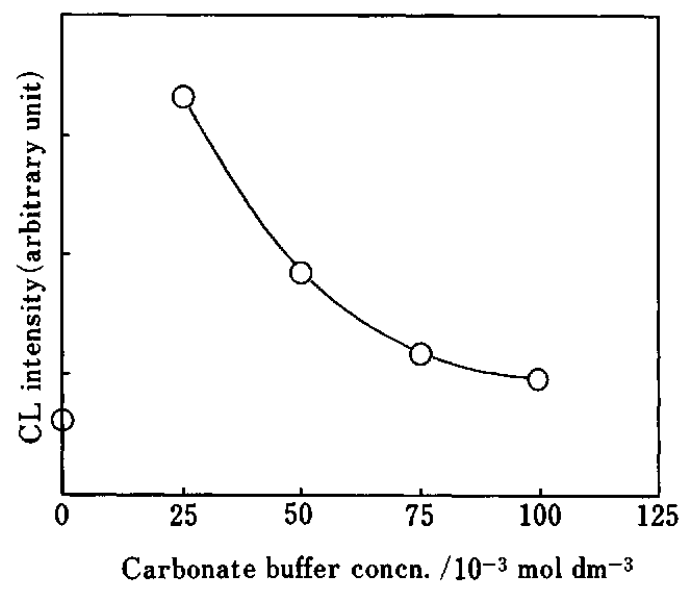

Fig. 3 Relationship between sample buffer concentration and CL intensity. Capillary, $80 \mathrm{~cm}, 50 \mu \mathrm{m}$ i.d., fused silica; applied voltage, $20 \mathrm{kV}$; running buffer, $100 \mathrm{mM}$ carbonate (pH 9.0); sample buffer, carbonate (pH 9.0); sample, $4 \times$ $10^{-7} \mathrm{M}$ BSA solution containing $2 \times 10^{-5} \mathrm{M}$ TRITC. TCPOCL reaction conditions as in Fig. 2.

basis of the migration times known for the individual RITC- and TRITC-protein complexes, peaks (a), (c), and (f), as well as peaks (b), (d), (e), (g), (h), and (i) in Fig. 2 were identified as being due to TRITC, RITC, and TRITC, and as TRITC-BSA, RITC-Ova, RITC- $\alpha$-lacta, TRITC-B $\gamma$ G, TRITC-BSA, and TRITC- $\alpha$-lacta complexes, respectively.

Samples containing various amounts of BSA and a definite amount of each dye-stuff were analyzed by the present method, and a linear calibration curve for the $\mathrm{CL}$ intensity of BSA was obtained for both dyes. Using the calibration curve, the BSA in the concentration range of up to $2 \times 10^{-6} \mathrm{M}$ could be determined by RITC with a detection limit of $2 \times 10^{-8} \mathrm{M}$; the BSA in the concentration range of up to $1 \times 10^{-6} \mathrm{M}$ could be determined by TRITC with a detection limit of $1 \times 10^{-8} \mathrm{M}$. Since approximately $20 \mathrm{nl}\left(2 \times 10^{-8} \mathrm{dm}^{3}\right)$ of the sample was taken by siphoning for $15 \mathrm{~s}$ at a height difference of $15 \mathrm{~cm}$, the absolute amount of detectable BSA was $400 \mathrm{amol}$ for RITC and $200 \mathrm{amol}$ for TRITC, respectively.

An optimization for stacking of a TRITC-BSA complex was carried out as follows: (1) Mixed sample solutions of each definite amount of TRITC and BSA were prepared as carbonate buffer solutions of 100,75 , 50 , and $25 \mathrm{mM}$ (pH 9.0); the resulting sample solutions were subjected to a CZE-CLD system where a $100 \mathrm{mM}$ carbonate buffer ( $\mathrm{pH} 9.0$ ) was used as a running buffer. The relationship between the sample buffer concentration and the $\mathrm{CL}$ intensity is shown in Fig. 3, including the result obtained for a carbonate buffer-free sample. Considering the result shown in Fig. 3 and the expected rise in the temperature inside a capillary tube due to a decrease of the buffer concentration, a $25 \mathrm{mM}$ carbonate buffer was chosen in the following experiment. (2) The relationship between the injection time and the CL intensity was examined in order to determine the stacking 


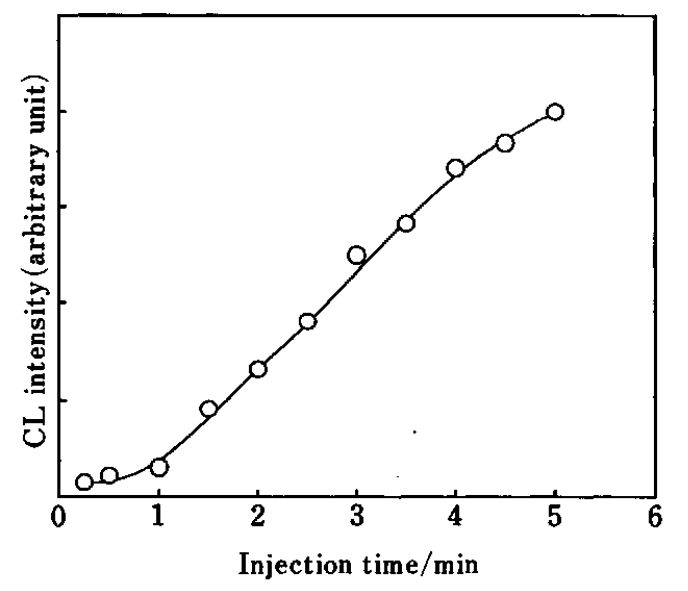

Fig. 4 Relationship between injection time and CL intensity. Capillary, $80 \mathrm{~cm}, 50 \mu \mathrm{m}$ i.d., fused silica; applied voltage,

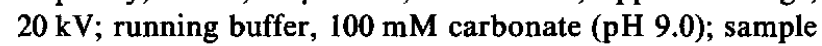
buffer, $25 \mathrm{mM}$ carbonate ( $\mathrm{pH} 9.0$ ); sample, $4 \times 10^{-7} \mathrm{M}$ BSA solution containing $2 \times 10^{-5} \mathrm{M}$ TRITC. TCPO-CL reaction conditions as in Fig. 2.

effect; the results are shown in Fig. 4. An injection time of 4 min was selected, since the CL intensity increased with increasing injection times. However, the separation of the TRITC-BSA complex from TRITC deteriorated.
Various BSA samples containing a definite amount of TRITC were analyzed by the present method, and a linear calibration curve was obtained for the $C L$ intensity against the BSA amount. Using the calibration curve, the BSA in the concentration range of up to $1 \times 10^{-7} \mathrm{M}$ could be determined with a detection limit of $6 \times 10^{-9} \mathrm{M}$.

In summary, (1) TRITC was more sensitive than RITC for the detection of proteins, and (2) by the proposed method using the stacking effect, BSA could be estimated with a detection limit of $6 \times 10^{-9} \mathrm{M}$.

\section{References}

1. T. Hara, H. Nishida, S. Kayama and R. Nakajima, Bull. Chem. Soc. Jpn., 67, 1193 (1994).

2. R-L. Chein and D. S. Burgi, Anal. Chem., 64, 489A (1993).

3. D. S. Burgi and R-L. Chein, Anal. Chem., 63, 2042 (1991).

4. T. Hara, S. Okamura, S. Kato, J. Yokogi and R. Nakajima, Anal. Sci., 7 (supplement), 261 (1991).

5. T. Hara, J. Yokogi, S. Okamura, S. Kato and R. Nakajima, J. Chromatogr., 652, 361 (1993).

(Received May 2, 1994)

(Accepted July 27, 1994) 